Proceedings of the International Conference on Oxide Materials for Electronic Engineering, May 29-June 2, 2017, Lviv

\title{
Synthesis and Properties of Mesoporous Maghemite
}

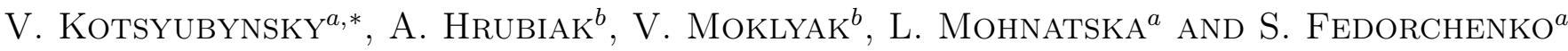 \\ ${ }^{a}$ Vasyl Stefanyk Precarpathian National University, 57 Shevchenko Str., Ivano-Frankivsk, 76018, Ukraine \\ ${ }^{b}$ Institute of Metal Physics, National Academy of Science, 36 Acad. Vernadsky Boul., Kyiv, 03680, Ukraine
}

Mesoporous maghemite $\left(\gamma-\mathrm{Fe}_{2} \mathrm{O}_{3}\right)$, obtained by thermal decomposition of iron citrate xerogel hydrate, was investigated by X-ray diffraction, scanning electron microscopy, the Mössbauer and impedance spectroscopies and low temperature nitrogen adsorption. The influence of precursor molar concentration on the material morphology, crystalline and magnetic microstructures and electric conductivity was studied. Obtained results open up the possibility for synthesis of ultrafine $\gamma-\mathrm{Fe}_{2} \mathrm{O}_{3}$ with controlled structural and morphological characteristics.

DOI: 10.12693/APhysPolA.133.1035

PACS/topics: 75.47.Lx, 75.75.Cd, 61.46.-w, 81.16.Be

\section{Introduction}

Nanostructured iron oxides, in particular maghemite, have numerous applications - both biomedical (magnetic hyperthermia [1], drug and gene delivery [2], magnetic resonance imaging) and technological (memristors [3], cathode materials). The efficiency of material depends on the particle size and can be expanded by nanostructured systems obtaining with specified morphological characteristics (increased surface area or predicted porous structure). This article considers the experimental aspects of the obtaining the mesoporous maghemite with morphologically sensitive electrical conductivity and magnetic microstructure.

\section{Experimental details}

$\gamma-\mathrm{Fe}_{2} \mathrm{O}_{3}$ samples were prepared by sol-gel method via aqueous route [4]. The first stage included the slow mixing of $\mathrm{Fe}\left(\mathrm{NO}_{3}\right)_{3} \cdot 9 \mathrm{H}_{2} \mathrm{O}$ and $\mathrm{C}_{6} \mathrm{H}_{8} \mathrm{O}_{7} \cdot \mathrm{H}_{2} \mathrm{O}$ solutions (molar ratio 1:1, molar concentrations - 0.025, 0.1, 0.3, $0.5 \check{\mathrm{E}}$ ) and the further ageing of obtained sol at $60^{\circ} \mathrm{C}$ in air to formation of the iron citrate hydrate xerogels. On the next stage iron citrate xerogels were annealed at $200^{\circ} \mathrm{C}$ during $1 \mathrm{~h}$ in air. The obtained materials were labeled accordingly to the precursor molarity $(0.025$, $0.1,0.3,0.5$ É, respectively) and investigated by X-ray diffraction (XRD), the Mössbauer and impedance spectroscopies, scanning electron microscopy and low temperature nitrogen adsorption.

\section{Results and discussion}

The obtained materials are monophase $\gamma-\mathrm{Fe}_{2} \mathrm{O}_{3}$ (Fig. 1). Average sizes of X-ray coherent scattering regions growth with the increase of precursors molar concentration: $6 \pm 2$ for $0.025 \mathrm{M}$ and $0.1 \mathrm{M}$ samples, $7 \pm 2$ for $0.3 \mathrm{M}$ and $12 \pm 2 \mathrm{~nm}$ for $0.5 \mathrm{M}$ samples. All materials are characterized by porous structure (Fig. 2). The tendency to porosity increasing with the enlarging ofthe

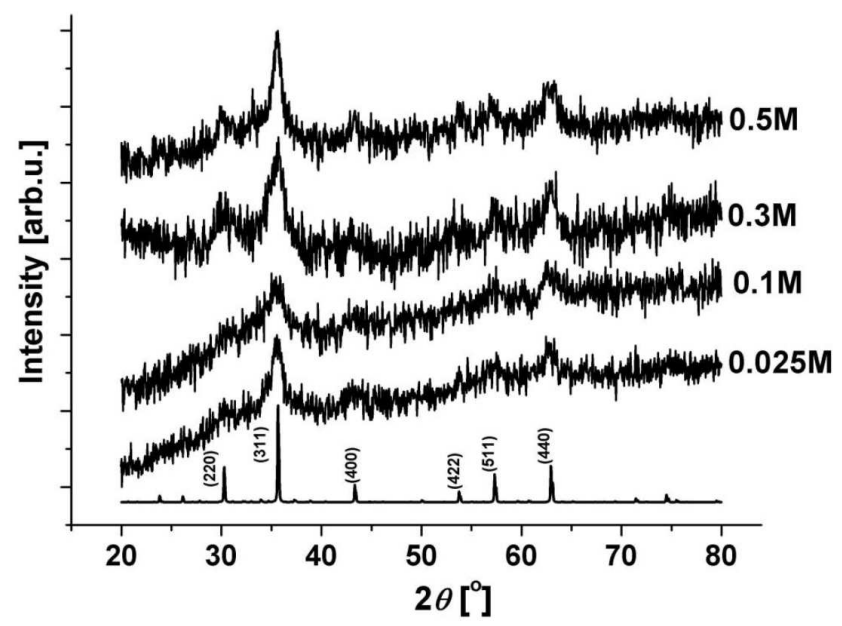

Fig. 1. XRD patterns of $\gamma-\mathrm{Fe}_{2} \mathrm{O}_{3}$ samples obtained at the different precursor molarity.

precursor molar concentration was observed for 0.025 , 0.1 , and $0.3 \mathrm{M}$ samples. It can be explained by the peculiarities of a gel formation. Slow aggregation regime leads to enlarging the quantity of interacting clusters and particles (reaction limited cluster aggregation mechanism is dominating). The increase of molar concentration at these conditions causes the sizes decrease of primary clusters at the gel formation stage [5]. The decomposition of metal-organic precursor during the dried gel annealing leads to mesoporous iron oxide formation with morphological properties depending on the precursors concentration. Large agglomerates and cracks are present on the sponge-like porous surface of $0.5 \mathrm{M}$ material. Specific surface areas of obtained materials (based on the BET method) vary depending on the precursors molar concentrations in a range $95-165 \mathrm{~m}^{2} / \mathrm{g}$ (Fig. 2). The decrease of specific surface area for $0.5 \mathrm{M}$ sample corresponds to particle enlarging. The similar behavior of specific surface area of magnetite nanoclusters as a function of precursor concentrations was observed in [6]. The pore sizes distributions for all samples are characterized by maximum at about of $5 \mathrm{~nm}$ (Fig. 3).

*corresponding author; e-mail: kotsyubynsky@gmail.com 


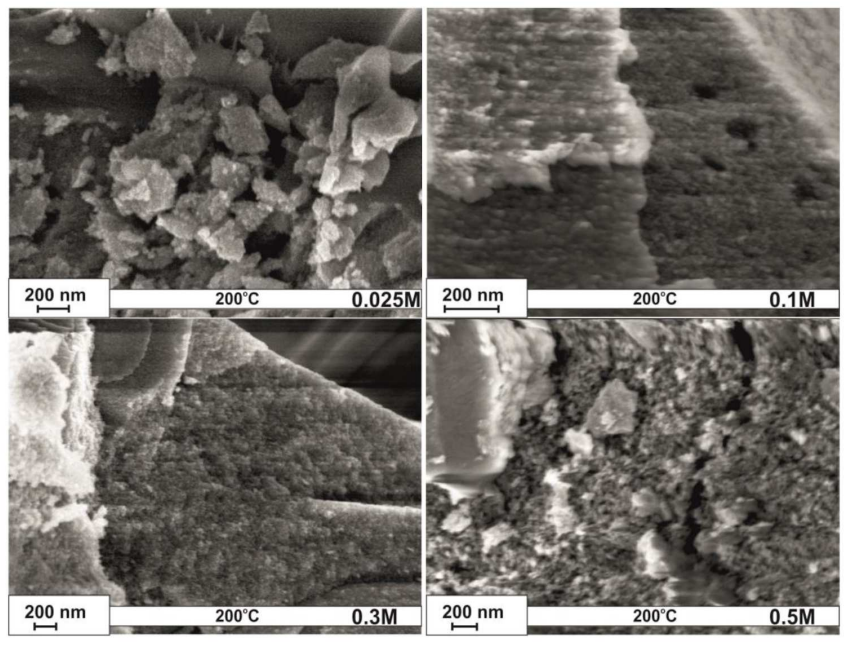

Fig. 2. SEM images of $\gamma-\mathrm{Fe}_{2} \mathrm{O}_{3}$ samples.

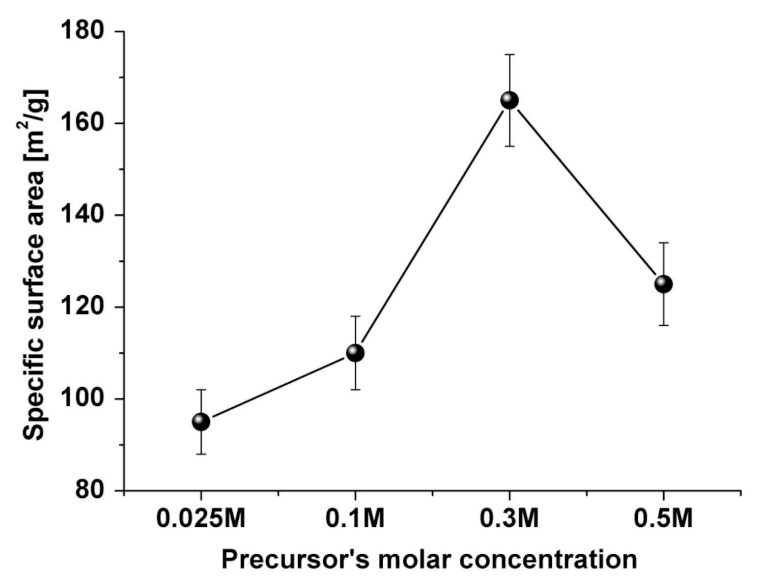

Fig. 3. Specific surface area of $\gamma-\mathrm{Fe}_{2} \mathrm{O}_{3}$ samples as a function of the precursor molarity.

The Mössbauer spectra of all samples are characterized by presence of a dominant doublet component that corresponds to resonance absorption by the nucleus of tetrahedral coordinated $\mathrm{Fe}^{3+}$ ions in the high-spin state (Fig. 4). The formation of doublet component is the result of sizes effects and superparamagnetism phenomena [4]. The obtained materials can be represented as a grid of interconnected monodomain clusters with fluctuated magnetic moments. The fluctuations cause the broadening of spectral components and disappearance of magnetic hyperfine splitting. Paramagnetic part of the each spectra consists of two doublet components (D1 and D2) with close values of isomeric shift and different values of quadrupole splitting (Table I). The difference can be explained by the localization of $\mathrm{Fe}^{57}$ nuclei with the different near surroundings in the inner and outer layers of the particles (clusters). A close approach for the Mössbauer spectra interpretation of maghemite nanoparticles has been used in [7]. The ratio between relative areas of these two doublet slightly depend on the precursors molar concentration.

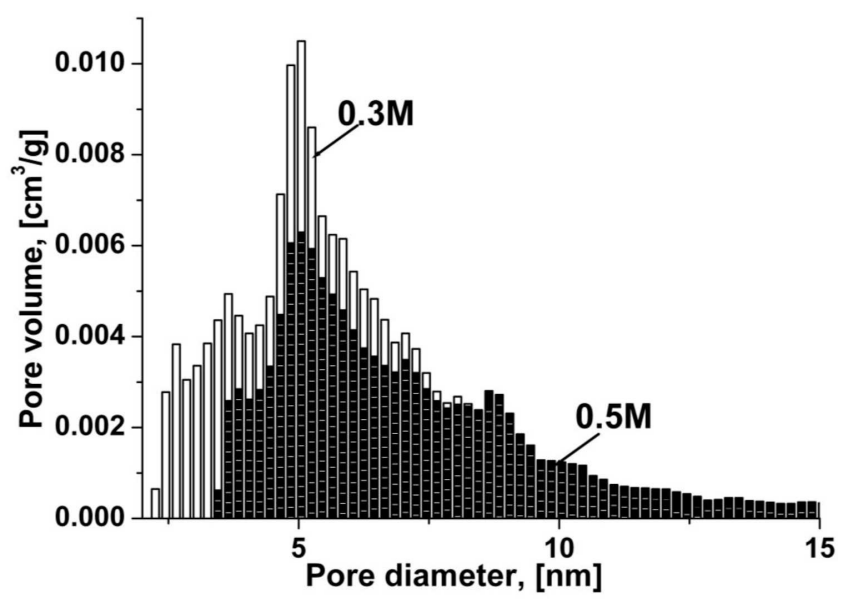

Fig. 4. Pore size distribution of $0.3 \mathrm{M}$ and $0.5 \mathrm{M}$ $\gamma-\mathrm{Fe}_{2} \mathrm{O}_{3}$ samples.

Parameters of hyperfine interactions for TABLE I mesoporous $\gamma-\mathrm{Fe}_{2} \mathrm{O}_{3}$ samples.

\begin{tabular}{c|c|c|c|c|c}
\hline \hline Sample & Component & $\begin{array}{c}\delta \\
{[\mathrm{mm} / \mathrm{s}]}\end{array}$ & $\begin{array}{c}\Delta \\
{[\mathrm{mm} / \mathrm{s}]}\end{array}$ & $\begin{array}{c}\omega \\
{[\mathrm{mm} / \mathrm{s}]}\end{array}$ & $S[\%]$ \\
\hline \multirow{2}{*}{$0.025 \mathrm{M}$} & $\mathrm{D} 1$ & 0.33 & 0.71 & 0.35 & 16 \\
\cline { 2 - 6 } & $\mathrm{D} 2$ & 0.32 & 0.95 & 0.90 & 84 \\
\hline \multirow{2}{*}{$0.1 \mathrm{M}$} & $\mathrm{D} 1$ & 0.33 & 0.63 & 0.37 & 17 \\
\cline { 2 - 6 } & $\mathrm{D} 2$ & 0.33 & 0.98 & 0.73 & 83 \\
\hline \multirow{2}{*}{$0.3 \mathrm{M}$} & $\mathrm{D} 1$ & 0.33 & 0.70 & 0.35 & 16 \\
\cline { 2 - 6 } & $\mathrm{D} 2$ & 0.33 & 0.97 & 0.82 & 84 \\
\hline \multirow{3}{*}{$0.5 \mathrm{M}$} & $\mathrm{D} 1$ & 0.33 & 0.60 & 0.28 & 5 \\
\cline { 2 - 6 } & $\mathrm{D} 2$ & 0.33 & 0.94 & 0.74 & 49 \\
\cline { 2 - 6 } & $\mathrm{S} 1$ & 0.32 & -0.04 & 1.10 & 41 \\
\cline { 2 - 6 } & $\mathrm{S} 2$ & 0.34 & -0.20 & 0.22 & 5
\end{tabular}

The increase of precursors molar concentrations up to $0.5 \mathrm{M}$ leads to particle enlarging and iron ions appearance in magnetically ordered state. As a result, spectrum of $0.5 \mathrm{M}$ sample is a superposition of two doublets and two sextets (S1 and S2) components. At the same time we can qualitatively predict the smallest average particle size for $0.1 \mathrm{M}$ samples as evidenced by full absence of components corresponding to iron ions in magnetic ordered state.

The frequency dependences of the complex conductivity $\gamma-\mathrm{Fe}_{2} \mathrm{O}_{3}$ samples obtained at the different precursors molar concentration (Fig. 5) are typical for disordered dielectrics and semiconductors - weak changes of the conductivity at low frequencies and the increase with frequency enlarging. For interpretation of electricalrelaxation phenomena for $\mathrm{dc}$ and ac conductivities the Jonscher power law was used: $\sigma(\omega)=\sigma_{d c}\left[1+\left(\frac{\omega}{\omega_{h}}\right)^{s}\right]$, where $\sigma_{d c}$ is the $d c$ conductivity, $\omega_{h}$ is the hopping frequency of the charge carriers, and $s$ is a frequency exponent parameter in the range $0<s<1$ characterizing the deviation from the Debye behavior and measurement of the interionic coupling strength [8]. For all materials $s$ is close to 1 that indicates small polarons hopping mecha- 
nism of conductivity (model of correlated barriers). The dc conductivities and charge carriers hopping frequencies despite withthe precursor molarity increase due to enlarging of the particles (Fig. 6). Law charge carriers hopping frequency have the local maximum for the $0.1 \mathrm{M}$ sample and decrease with the next particle size enlarging. The maximal hopping frequency for $0.1 \mathrm{M}$ sample corresponds to minimal average particle sizes (Fig. 7). The average particle size of synthesized materials depends on the precursor molarity so the possibility of its conductivity purposefully changing is opened.

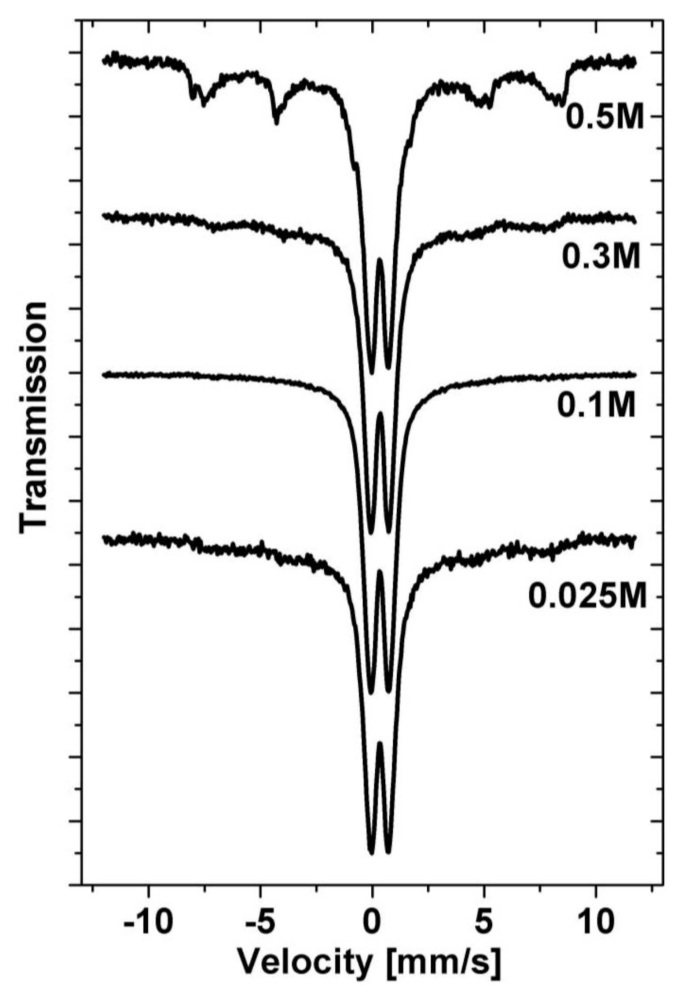

Fig. 5. Mössbauer spectra of mesoporous $\gamma-\mathrm{Fe}_{2} \mathrm{O}_{3}$ samples.

\section{Conclusions}

The variation of the precursor $\left(\mathrm{Fe}\left(\mathrm{NO}_{3}\right)_{3} \cdot 9 \mathrm{H}_{2} \mathrm{O}\right.$ and $\left.\mathrm{C}_{6} \mathrm{H}_{8} \mathrm{O}_{7} \cdot \mathrm{H}_{2} \mathrm{O}\right)$ molar concentration during ultrafine $\gamma$ $\mathrm{Fe}_{2} \mathrm{O}_{3}$ sol-gel synthesis allows to obtain the superparamagnetic materials with the predicted morphological and electrical characteristics. The growth of the precursor molarity from $0.025 \mathrm{M}$ to $0.5 \mathrm{M}$ leads to average particle sizes enlarging in a range $6-12 \mathrm{~nm}$. The specific surface areas of obtained materials change nonlinear in a range of $95-165 \mathrm{~m}^{2} / \mathrm{g}$, the pore sizes distributions have a maximum at about $5 \mathrm{~nm}$. The dc conductivities and charge carriers hopping frequencies despite withthe precursor molarity increase. The molar concentration increase at the conditions of reaction limited cluster slow aggregation causes the iron oxides particles decrease.

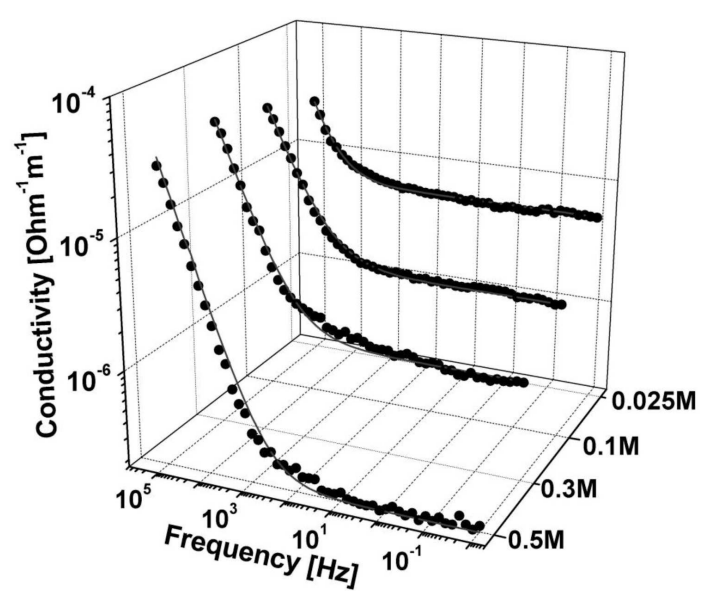

Fig. 6. The frequency dependences of the electric conductivity of $\gamma-\mathrm{Fe}_{2} \mathrm{O}_{3}$ samples.

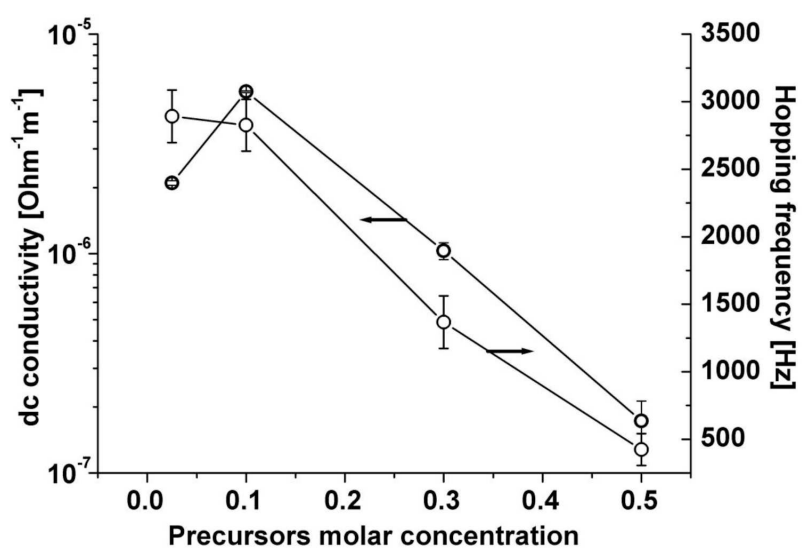

Fig. 7. The dc conductivity and charge carriers hopping frequency of $\gamma-\mathrm{Fe}_{2} \mathrm{O}_{3}$ samples vs. precursors molar concentration.

\section{References}

[1] R. Hergt, S. Dutz, R. Müller, M. Zeisberger, J. Phys. Condens. Matter 18, S2919 (2006).

[2] S.C. McBain, H.H. Yiu, J. Dobson, Int. J. Nanomed. 3, 169 (2008).

[3] T.H. Kim, E.Y. Jang, N.J. Lee, D.J. Choi, K.J. Lee, J.T. Jang, J. Cheon, Nano Lett. 9, 2229 (2009).

[4] V. Kotsyubynsky, V. Moklyak, A. Hrubiak, Mater. Sci.-Pol. 32, 481 (2014).

[5] J. Primera, A. Hasmy, T. Woignier, J. Sol-Gel Sci. Technol. 26, 671 (2003).

[6] S.I.U. Madrid, U. Pal, F. Sánchez-De Jesús, Adv. Nano Res. 2, 187 (2014).

[7] I.S. Lyubutin, S.S. Starchikov, T.V. Bukreeva, I.A. Lysenko, S.N. Sulyanov, N.Y. Korotkov, A.L. Vasiliev, Materialwiss. Werkstofftech. 45, 225 (2014).

[8] J.C. Dyre, T.B. Schrøder, Rev. Mod. Phys. 72, 873 (2000). 